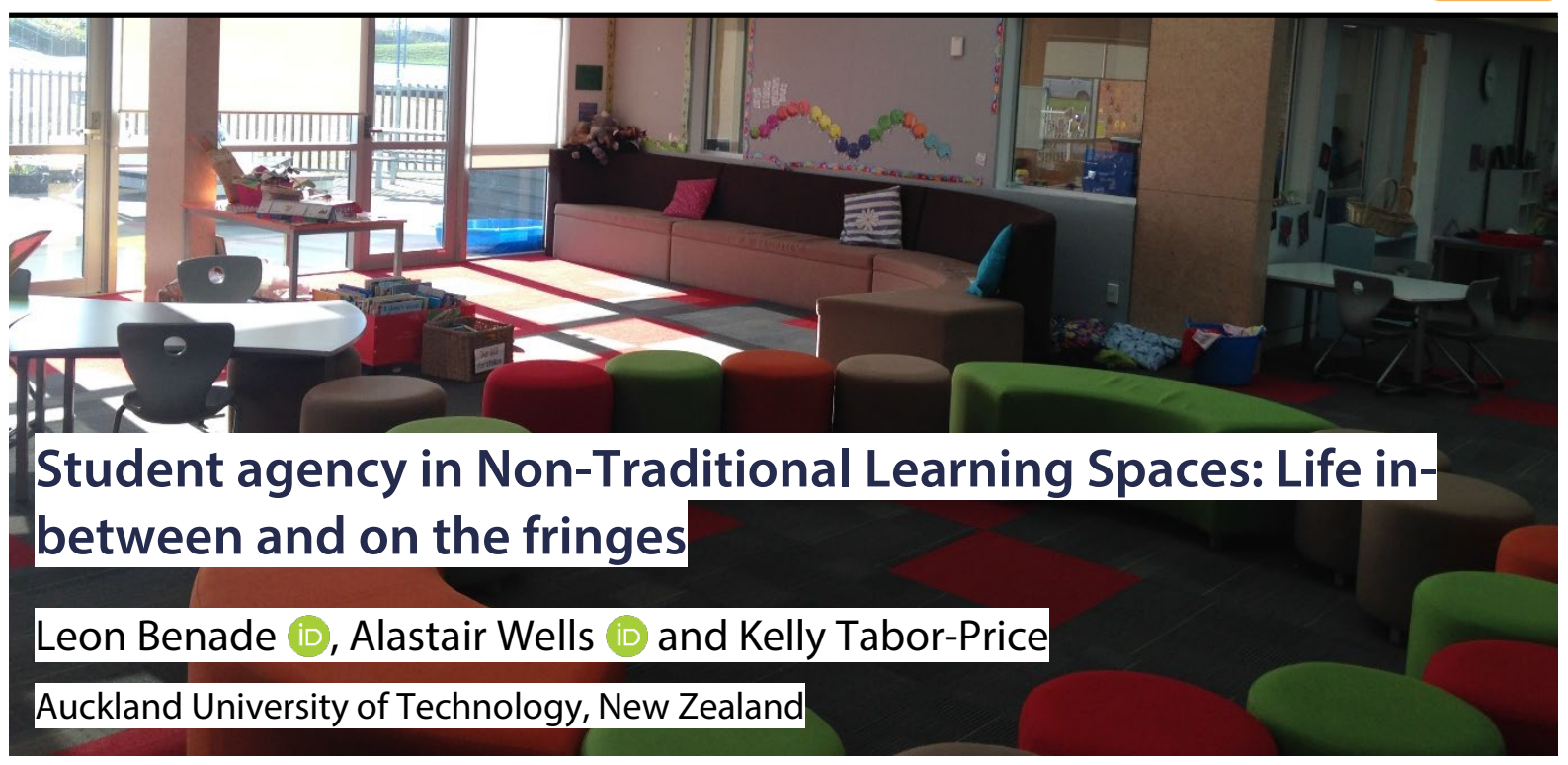

Photo by author

\begin{abstract}
Non-Traditional Learning Spaces (NTLS) boasting innovative building designs that embody an array of modern technology, visually and functionally sever schooling practices from the factory model, suggesting a reconceptualisation of what it is to 'do school' at the level of research and practice. This process of reconceptualisation includes reconceptualised pedagogical practice, and the development by students of spatial competency. In this regard, 'student agency' plays a significant role. For some years now, student agency has been prioritised by education policymakers and reformers alike, and it is a concept that has become central to questions relating to teacher practice and student life in NTLS. In this article, agency is construed as a contestable, politically domesticated construct that is reduced to student engagement with prescribed, mainstream and 'official' educational processes. We argue, instead, that the notion of student agency be taken beyond this sanitised usage, so that the broader complexity of agentic practices be understood. Understanding student agentic practice in NTLS is a critical dimension of the overall aim of more rigorously theorising spatiality, and in this article, we begin the task of considering how student agentic practices can be included in achieving that aim. Therefore, we discuss and explore the complexities of agentic student behaviour, considering where it is located in the complex relationship between the development of student spatial competence and mere compliance in NTLS.
\end{abstract}

\section{KEYWORDS}

Non-Traditional Learning Spaces; agency; spatial competence; spatial literacy

\title{
Introduction: The role of policy
}

'Non-Traditional Learning Spaces' (NTLS) refers to the innovative spatialisation of educational spaces. These spaces present a newly-configured spatial typology (open flexible spaces) in contrast to the tightly ordered typology of traditional cellular classrooms. NTLS is the short-hand used in this article to describe spaces that are also referred to as 'Innovative Learning Environments' (ILE), Flexible Learning Environments' (FLE) and 'New Generation Learning Environments' (NGLE), to name a few. Generally designed in 'open-plan' style, these technologically-enriched learning 
environments are visually connected and are designed to create flexible configurations that enable students and teachers to collaborate and problem-solve in groups. Digital and electronic work, including research and writing, mesh with socio-cultural pedagogies, reflecting the Vygoskian notion of learning and knowledge being constructed in a social context. These spatial typologies encourage pedagogical activities that reflect non-traditional synergies between teacher direction and student agency. That is to say, the traditional modality of the teacher instructing passive students 'from the front' is replaced by the modalities indicated above.

NTLS have gained significant momentum internationally, arising within a neo-liberal environment where education policy is utilised as a way to prepare young people for the knowledge economy of the future (Arnesen et al., 2020; Chapman et al., 2014; Martin, 2006; McPherson \& Saltmarsh, 2017; Mulcahy \& Morrison, 2017). In this sense, NTLS have emerged as a means to correct the ills of industrialised teaching typified by hierarchical knowledge transmission and constraints on student agency (Arnesen et al., 2020; Chapman et al., 2014; Deed et al., 2014; McPherson \& Saltmarsh, 2017). This policy shift has been tightly woven into discourses of collaboration, creativity, disruption, future focused learning, flexibility, a shift towards heuristic pedagogies and student agency (Campbell, 2020; Chapman, et al., 2014; Charteris \& Smardon, 2018; Deed et al., 2014). NTLS visually and functionally sever schooling practices from the factory model, their designs embodying wider technological change and the reformist trend to emphasising skill development and social cohesion in education. NTLS are thus a catalyst for reimagining what it is to 'do school' and to be 'educated'.

The physical manifestations of the 'building revolution' are not entirely novel, however. In Europe, for instance, the Building Schools for the Future (BSF) programme in the United Kingdom was launched in 2003. The BSF programme was intended to replace ageing school facilities that were considered unable to meet the needs of $21^{\text {st }}$ century students (Mahony \& Hextall, 2013). At a similar time, the 'iconic' (Leiringer \& Cardellino, 2011) Hellerup School was built in Copenhagen, Denmark. In Portugal, the Secondary Schools Modernisation Programme (SSMP), was launched in 2007 to provide physical facilities that could positively improve education practice (Veloso et al., 2014). In 2009, the Rudd government in Australia launched the ambitious Building the Education Revolution (BER) programme (Lewis et al., 2014), while in New Zealand, the current shift towards modern building designs can be traced back to a 'learning studio' pilot project undertaken by the Ministry of Education in 2008 (Ministry of Education, 2021).

The development of learning spaces that break almost completely with traditional notions of 'classroom' and 'school' necessarily suggests that what it is to 'do school' at the level of research and practice has to be reconceptualised. Yet, in respect of the former, much learning environments research remains under-theorised (Benade, 2021b). In relation to the latter, although bureaucrats and designers alike believe that the provision of modernised educational facilities will fundamentally alter pedagogical practices, this assumption is a policy pipe-dream. It has been demonstrated there is not a linear relationship between building design and pedagogy (Benade, 2017; Woolner et al. 2012). Nonetheless, complex links exist between material space and pedagogy (Charteris \& Smardon, 2018; Mulcahy \& Morrison, 2017; Tondeur et al., 2017). The nature and influence of these links deserve critical consideration, particularly as NTLS prompt the reconceptualisation of pedagogical practice, and the development by students of spatial competency. In this regard, 'student agency' plays a significant role.

Agency, we contend, is a concept that reflects the multiplicities of NTLS. Philosophical and theoretical reflection on agency encourages us to invoke de Certeau (1984) and to reflect on the mundane everydayness of school life in NTLS in a way that reaches beyond the strategic discourses of architects and bureaucrats. This opens a tactical opportunity to focus in a philosophical way on notions of $21^{\text {st }}$ century teaching and learning, and to challenge the ways education policymakers and reformers alike have prioritised 'student agency'. In these hands, this construct is politically domesticated, understood as student and learner involvement in, 'ownership' of, and engagement 
with, prescribed, mainstream and 'official' educational processes. We argue, instead, that the notion of student agency be taken beyond the sanitised and tokenistic concept of 'voice and choice', so that the broader complexity of agentic practices be understood. Despite being under-theorised, spatial practice is a foundational and essential factor for consideration when engaging in both teaching and learning (Benade, 2019; Bradbeer, 2016; Imms et al., 2016; Leighton \& Byers, 2020; Martin, 2006; McGregor, 2004; Mulcahy \& Morrison, 2017; Rasmussen, 2019; Wood, 2019). While attention has been paid in research to the evolution of pedagogy and changes to teachers' thinking in NTLS (for example, Benade, 2017; Imms et al., 2016; Leighton \& Byers, 2020; Leiringer \& Cardellino, 2011; Young et al., 2020), here we have sought to understand and theorise student spatial practices, by thinking about the ways student agency, under the influence of conscious decision making by students themselves, could be practiced in NTLS. Understanding student agentic practice in NTLS is a critical dimension of the overall aim of more rigorously theorising spatiality and emergent notions of spatial literacy, and in this article, we begin the task of considering how student agentic practices can be included in achieving that aim. Therefore, we discuss and explore the complexities of agentic student behaviour, considering where it is located in the complex relationship between the development of student spatial competence and mere compliance in NTLS. Critical to deepening the discourse on student agentic practice in NTLS, it is important that in-between and fringe spaces be more closely considered for what their role might mean for agency. We see the production of this theoretical article as a precursor to undertaking field work that engages with students in NTLS.

\section{The role of design}

Policy-makers in some jurisdictions have been encouraged by the Innovative Learning Environments project of the Centre for Educational Research and Innovation (CERI) (Organisation for Economic Cooperation and Development [OECD], 2013, 2017). In a confluence of thinking, pedagogical change and innovation in education has been linked to the view that educational facilities can be an enabler of pedagogical change and educational reform (Benade, 2021a; Wells, 2018). In our respective field work with architects responsible for designing school projects, we have found that these designers have developed a keen interest in education and supporting the work of educators. They have sought to better understand pedagogical concepts, such as inquiry-based, student-directed, and collaborative approaches to learning that support students to become autonomous and self-directed (Benade, 2021a; Wells, 2018). These findings are echoed in other research (Dovey \& Fisher 2014; Nair, 2014). Architects regard their designs to be enablers of practice (Benade, 2019; Minero, 2018; Wells, 2018) by suggesting to users how the built environment may be utilised. In this sense, designers believe a school building can act as a non-neutral socially produced spatial affordance that educates more generally too (Benade, 2019; Minero, 2018; Wells, 2018), and that the potential for agentic behaviour arises from the interplay of the built environment and its occupants.

In this respect, innovative school design can, for example, activate positive citizenship (Nair, 2014), while flexible and comfortable learning facilities located in attractive outdoor settings can support creative curriculum development and delivery, effectively reducing stress and increasing motivation (Minero, 2018), simultaneously ensuring positive behaviour (Nair, 2014). Innovative educational facilities design supports community development (Tanner, 2009), by the creation of a heighted sense of connectivity, using the devices of visual vertical and horizontal transparency (Benade, 2019, 2021a; Minero, 2018; Wells, 2018). Seeing others at work and play, provides users a sense of belonging to a larger whole (Benade, 2019; Wells, 2018), while also removing the traditional barriers between academic and non-academic activity (Minero, 2018). The presence of circulation and gathering spaces, such as wide stair-cases, plaza-style and large social spaces, enable the users of these spaces to meet formally and informally, creating opportunities to retire to remote areas, where wireless learning is encouraged in the midst of uncongested activity and movement (Tanner, 2009; Wells, 2018), further blurring traditional notions of work and leisure. 
This (seemingly ebullient) discourse on the role of design represents the perspectives of designers - both those who have engaged in our research projects, and those whose views appear in other, cited research above. This design perspective is necessarily one that is motivated to some degree by professional self-interest - that of the contracted design firm. For example, commitment to questions of school and community participation will be secondary to the designer's commitment to the contracting bill-payer, such as the Ministry of Education (Benade, 2021a). This is not to suggest that the views of designers expressed here are disingenuous - their belief in innovative progress and the enabling possibilities of design are sincerely posited by these actors and may possibly be hard-wired into their education by the design studio pedagogy of architectural schools (Koch et al., 2002). They may also convey or transfer their experiences of designing modern corporate facilities to their work of designing educational facilities (Wells, 2018), thus implicitly conveying the imaginary of the ' $21^{\text {st }}$ century workplace' to education. Hence notions of 'remote working' and even 'hot-desking' may implicitly influence the design of schools. Recent learning environments research in relation to the 'spatial turn' in education facilities design has done little to subject the role of architects to critical scrutiny - in fact, the views and roles played by architects who are responsible for designing the current examples of NTLS, are not widely reported or reflected on in scholarly literature. To illustrate the point, some examples refer to innovative learning environment design yet almost wholly exclude reference to the designing architects (Barrett, et al., 2019; French et al., 2020; Pearlman, 2010). Others that do engage more overtly with designers are more concerned with positively contrasting the 'languages' of educators and architects (Newton, 2009; Wright, et al., 2021; Young et al., 2020).

This rather one-sided discourse leaves us with the underpinning narrative of designers (and the bureaucrats who utilise their services), that NTLS enable teachers to enact pedagogical change and embrace spatial practices that will support learning in flexible and open spaces (Benade, 2019; Bradbeer, 2016; Campbell, 2020; Chapman, et al., 2014; Charteris \& Smardon, 2018; Deed et al., 2014; Imms et al., 2016; Leighton \& Byers, 2020; Mameli et al., 2020). Meshing the design argument that the traditional school building is irrelevant (Moore \& Lackney, 1993; Nair, 2014), with the macro-level work of organisations such as the OECD, and the work of politicians and bureaucrats at the local level, has, nonetheless, given rise to a distinctly new and different critical orientation for education research - that of spatiality.

\section{NTLS and questions of spatiality}

The 'classroom' has been a taken-for-granted fact of school life, in part, suggests Newton (2009), because of its pervasive presence in teachers' lives, contributing to researchers neglecting to actively include classroom space in their studies. The 'spatial turn', however, increasingly evident in the past decade, invites education researchers to think about spatiality, or the spaces, real and virtual, in which pedagogical activity occurs. Arguably though, spatial theorising in educational contexts is not well developed (Benade, 2021b). Just as 'the classroom' is taken-for-granted, so too, 'learning space'. In large measure, spatiality is the purview of geographers (just as 'temporality' may be the purview of historians), so it is to geographers we turn to for clarity. Smith (1990) revealed how the discipline of geography had conceptualised space as an objective entity, existing independently of human behaviour and thought. Smith ascribed this tendency to Western thinking that sought to sever traditional views interlinking concepts of space, place and social relations.

Lefebvre's (1991) ground-breaking 1974 work, The Production of Space, provided the formulation of his much-cited conceptual triad of spatial practice, (which 'ensures continuity and some degree of cohesion... guaranteed level of competence and a specific level of performance', [p. 33]); representations of space ('tied to...knowledge, to signs, to codes' [p. 33]). and representational space ('...linked to the clandestine or underground side of social life' [p. 33]). This triad represented his effort to demonstrate a dialectic relationship between space and social practice and his focus on the ontology of everyday life, de-emphasising the epistemological focus 
on geometric space, which he critiqued. As Lefebvre argued for socially produced space, he was correspondingly of the view that social relations are affected by space, and that human experience of space was holistic, not fractured or compartmentalised. Human understanding of space is derived from mental conceptions and through social relations, but Lefebvre inserted lived space between these.

Lefebvre opened possibilities to reconceptualise the relationship between the social and the spatial and to develop socio-material analyses of space, in the process envisaging a new ontology of space. Hence, it has been possible to challenge simplified understandings of spatial behaviour in terms of cause and effect, where space stimulates human interactions within it (Bradbeer, 2016; McGregor, 2004; Rautio, 2014). Theoretical formulations drawing on material analyses of spatiality show the distinction between space and social practice as blurred (Rautio, 2014), enabling complex appreciations of space and social practice, underpinned by the notion that space is in reciprocal relationship with those that use it. This usage, however, does not arise ready-packaged, as it were, but depends on the development of spatial literacy.

\section{The significance of spatial literacy}

Wood (2019) suggests that the openness and flexibility of NTLS designs offer the user freedom to make choices. Arguably, however, the shift from the rigidities of traditional spaces is challenging to teachers and students. While Chapman et al. (2014) found that teachers in their study believed students do not have the 'innate competencies to work collaboratively' (p. 43), and may require instruction on the skills required to use the flexible spaces for learning, actually, teachers themselves are inclined to avoid collaboration, suggesting that spatial competencies among teachers in NTLS is an area of practice that needs attention and support (Arnesen et al., 2020; Benade, 2019; Bradbeer, 2016; Campbell, 2020; Chapman et al., 2014; Charteris \& Smardon, 2018; Imms et al., 2016; Leighton \& Byers, 2020; Martin, 2006; McGregor, 2004; Ralph \& Levinson, 2019). Campbell (2020), for instance, identified that teachers in a new NTLS were unaware of the constructivist pedagogies underpinning NTLS thinking, and lacked cohesive understanding of the purposes or reasons behind the development of their NTLS.

Earlier research evidence rejects any deterministic relationship between altered space and pedagogical practice or thought (Woolner et al., 2012; Woolner et al., 2018), while other European studies suggest that traditional practices are retained even once teachers have commenced working in NTLS (Campbell, 2020; Sigurðardóttir \& Hjartarson, 2016; Veloso et al., 2014). Campbell (2020) sums up this situation well, noting that for some teachers, the NTLS is regarded as 'a simple extension of their normal teaching environment, taking with them customary lesson planning habits and classroom management techniques' (p. 199). Yet, the NTLS cannot be regarded, we argue, as simply an alternative space to the norm. Teachers must develop significant competence, so that they learn to 'read' this new space - what Imms et al. (2016) termed, spatial literacy. Similarly, just as the traditional role of the teacher is disrupted and perturbed by the NTLS, so too the conventional role of the student is upset by these advances in spatial design (Imms et al., 2016). Thus, students also must develop strategies for acting differently in NTLS. As Campbell (2020) discovered, students new to a NTLS and its alternative furnishing, may (ironically) seek out tables, rather than opting for beanbags or other non-traditional furniture options.

The way students do move about and take up places within the flexible space of a NTLS has been likened by Imms et al. (2016) to 'colonisation'. For these authors, this process is, however, the positive one associated with collaboration and peer-peer learning. Conversely, as suggested by Ralph and Levinson (2019), students who have little influence on determining how space is operated may seek to make it a site for rebellion. In this regard, de Certeau's (1984) notion of the subversive tactics employed to live within (rather than blatantly oppose) the strategies of officialdom make sense of the ways in which students might 'work the gap', suggesting that as everyday opportunities 
arise, students might use these moments to engage the spaces in ways not necessarily intended (Brogan, 2017; de Certeau, 1984). Indeed, students may appear complicit in their spatial practices, when in fact, they are not. This possibility raises questions concerning the ways students develop their spatial competencies and where the manifestations of their spatial practices are located on a continuum ranging from consciously agentic student decision-making to compliance with teacher direction and manipulation of student 'voice and choice'.

\section{Student agency in NTLS}

The concept of student agency, popularly articulated as a mantra of 'student choice and voice' under the aegis of a pedagogy of personalised learning, has prospered with the advent of the flexible designs of NTLS, that call for a significant and substantive reconceptualisation of the teaching and learning process. The popular notion of student agency lies close to the heart of what is intended by the ' $21^{\text {st }}$ century learner' (Charteris, 2019). It is a concept that embodies the imaginary of the selfdirected 'learner', capable of self-selecting and self-initiating learning tasks appropriate to meeting the desired educational objectives required to attain success, without the over-bearing direction of a teacher, hence agency's fit with NTLS, where learning environments cater to large numbers of students managed by multiple teachers. This imaginary of the 'self-directed learner' portrays agentic learners working synergistically with peers, and pro-actively sourcing support, such as that teachers are able to facilitate. Among the benefits of developing agentic student behaviour, suggests the OECD (2019), is its facility to 'help individuals achieve long-term goals and overcome adversity' ( $p$. 4). These popular discourses of student agency suggest that it can be imparted and developed by teachers, and that in students, it is an innate, 'dispositional' trait (Charteris \& Smardon, 2018; OECD, 2019).

The New Zealand Ministry of Education regards NTLS (innovative learning environments) as beneficial for their ability to offer agency to teachers and students (Te Kete Ipurangi, n.d.-a). Its definition of 'learner agency' encompasses having control over one's immediate environment, being influential and participating actively in one's own learning. The Ministry takes the view that an agentic learner has self-belief in the beneficial contribution of learning, that agentic learners can work with others, and recognise the influence of their actions and decisions on others and the wider environment (Te Kete Ipurangi, n.d.-b). An alternative view of agency is proposed by the keen proponent of the shift to NTLS, Mark Osborne (2016), who deemed these spaces to have the democratising effect of providing 'opportunities for learners to have a voice in the what, why, where, how and with whom of learning' (p. 6), that is, to promote agency.

Here we would seek to problematise these various, popular notions of agency, by pointing out that, despite their intrinsic appeal, they are notions that sit comfortably alongside concepts of Human Capital Theory and neoliberalism, that constitute individuals as rational choosers (homo economicus) who must simultaneously 'make their own luck' by a constant process of selfimprovement. As Brown et al. (2010) put it: 'Work and educational experience has to be packaged in a narrative of employability which involves constructing life stories of productive achievements and future promise that must be constantly sold to employers throughout a career' (p. 142). Furthermore, Charteris (2019) hinted at the democratising opportunities of NTLS being supplanted by these narrower conceptions of 'agency', driven by well-defined teacher input and selections working in the background to guide student choice. Definitions of agency that purport to promote student empowerment may thus actually imply student conformity to the intentions of the teacher, masterfully stage-managed in the background. To understand student spatial practices, we argue, a definition of student agency must go beyond a sanitised 'official' notion, to an understanding of agency that better captures the broader complexity of agentic practices. It is to a consideration of some of these complexities that we now turn. 


\section{Moving beyond the mundane: A complex appreciation of student agency}

Charteris and Smardon (2018), in a study of 38 New Zealand school principals, identified four agentic types ('Sovereign...Relational...Ecological...New Material', p. 56). The type they believe is most evident in their study of principals' responses is 'sovereign agency', an intrinsic, choice-driven state, facilitated by teachers, whereby students 'exert agency' as sovereign, autonomous beings. They argue cogently against this view of agency, widely popularised in educational psychology and deeply influential over initial teacher education. Their preference is to argue that some of the affordances of NTLS already mentioned lend themselves towards a type these authors describe as 'new material' (in line with their own identification with New Materialism). Their preferred sense of agency is 'always in flux and flow and is generated through a range of elements within schooling assemblages. It is co-produced in relations between objects, between humans and objects, and between humans' (Charteris \& Smardon, 2018, p. 56). While we acknowledge the weakness of the 'popular' sovereign notion, and are in sympathy with the new material notion, we want to pursue the notion of 'disposition' that these authors associated with the sovereign agent, which we assume is used by them as synonymous with 'innateness'. While we can understand how these two terms can be seen in this way, we want to indicate that dispositional learning, in an Aristotelian sense, can illustrate the aspect of agency that in fact perturbs conventional notions of agency, and, we will later go on to suggest, is implicated in some unintended consequences of the design and pedagogical intent of NTLS.

One way in which to understand how adherents of popular ('sovereign') notions of agency think about this concept is to recognise that they see agency as a quality that disposes students to act in ways that are in accord with the agency of popular wisdom. In this sense, they are adopting a 'head, heart, hands' (Singleton, 2015) approach. That is, the individual student has the cognitive understanding, the desire to act in accordance with that understanding, and the required skills to carry out the concept in action. Such action, it may be argued, eventually becomes habitual, and requires minimal prompting. Thus, the student understands, over time, what agency comprises of and why it is beneficial, has developed the skill required to act agentically, but most of all, takes up such action as a default setting - the student knows what to do in any given learning situation that requires agentic action. Effectively, the student resembles Foucault's (1994) self-governing individual capable of self-surveillance and self-correction. Beneath the surface of this account are several overlooked assumptions, however. These include the question of the content of the concept of agency, the definition of appropriate 'agentic behaviour' and the bounds that constitute the 'given situation' requiring agentic behaviour, including those constituted by the collection or ensemble of practices and exercises of power governing the mundane everydayness of school life. We would like to suggest that this failure to be critically attuned to these assumptions characterises the politically-sanitised understanding popularly held in the minds of many, if not most, teachers, school leaders, initial teacher educators, professional learning consultants and education curriculum bureaucrats. Probing the notion of dispositional action exposes some of these assumptions.

It is possible to discern some similarities between the account of just given of dispositional acts, and Aristotle's understanding of 'virtue', which he regarded as an expression of human excellence. For Aristotle, virtues come about, not by some inborn quality, but by habitual learning (Aristotle, 2014). Thanks to this learning, the individual comes to act freely and knowingly in a certain way. Indeed, the experience of learning repeatedly leads to the formation of habit, which is the disposition to act freely and knowingly (Aristotle, 2014). Renowned education philosopher, R. S. Peters (1970), described how this might occur, when he explained that children 'learn to act from others who know how to act, without understanding the reasons' (p. 314). Peters suggested that successful rule following leads to compliance with the rules. Critically, however, the realisation eventually dawns 'that rules are not transcendentally given as a part of the world order, but that there are reasons for them' (Peters, 1970, p. 315). This, we argue, is the important Aristotelian lynchpin that upsets the 'agency' of conventional education wisdom: the centrality of reason. For 
Aristotle, the capacity to reason is a human quality that underpins dispositional acts. While there may be a habitual disposition to act in certain ways, this does not mean such acts are unthinking or mechanical. Indeed, because Aristotle connected his account of dispositional acts to the attainment of moral virtue, he allowed for the possibility that some acts, such as anger, could be the correct response under certain conditions (Aristotle, 2014). On an Aristotelian account, rationality underpins dispositional acts, as it is present in the dimensions of cognitive knowledge and understanding, the process of choosing the correct course of action, and the skill that is exercised in undertaking that action. Dispositional acts are oriented to the attainment of the virtues, and their attainment secures human happiness, (though one should not be acting virtuously only to be happy, as happiness should be its own end [Aristotle, 2014]). 'Virtue, then, is a deliberately choosing state...one defined by a reason...' (Aristotle, 2014, II, 6, 1106 $36-1107^{\mathrm{a}} 1$ ).

The problem we are drawing attention to here is that the account of agency as it is conventionally used and articulated in education, is its prioritisation of habitual responses by students to contexts and situations created and managed by teachers, which brushes aside the role of 'right reason' (in Aristotle, reason used in pursuit of virtue)-indeed, possibly of reason altogether. We want to go on to show that in NTLS, there have arisen a host of unintended design consequences that may directly influence - and perturb - the conventional understanding and application of the concept of agency, because they permit the exercise of deliberate student choices. Specifically, 'inbetween' and fringe spaces may be the site of student acts that do not neatly conform to teacher control.

\section{In-between and fringe spaces}

Wood (2019) asserts that architecture is 'not the end, but a means to ends that will be taken up and shaped by people' ('How architecture and social, relational space might relate' section). Taking up the importance of relationality in space (highlighted earlier in reference to Lefebvre, 1991), Wood (2019) argues that thresholds are in-between spaces, relationally meaningful to those who use them, as they support informality. One may hesitate at a threshold; the threshold may mark the intersection of the formal and the informal; it may prompt a moment of reflection to contemplate what Monahan (2002) referred to as the 'built pedagogy', the intentional design choices that could vary from imposing limits to those that 'invite and almost demand that individuals appropriate space to their perceived needs' (Monahan, 2002, p. 5). Designers of innovative educational facilities intentionally design spaces of flow, movement and congestion (Benade, 2019), specifically blurring the lines between formal learning and social interaction. It is no surprise, therefore, that thresholds, and other informal 'in-between' spaces should be appropriated, as Monahan suggested, to the 'perceived needs' of the users of these spaces. Wood proposes further that thresholds can be both spaces of transition and 'meeting places': 'the idea of a threshold...can be both to gently structure a dialogue and a means for relating and valuing what lies on either side' (Wood, 2019, 'The inbetween, l'entre-deux and thresholds' section).

These ideas of informal and relational practices are acknowledged and embedded in the discourse around NTLS and $21^{\text {st }}$ century learning because they are considerations that, it is argued, can help improve learning (Arnesen et al., 2020; Ministry of Education, 2021; OECD, 2017). Indeed, the OECD asserts that students recognise that learning comes from both formal and informal means (OECD, 2017). Correspondingly, the design discourse emanating from architects and education bureaucrats that space and learning be regarded as increasingly borderless, and that design decisions consider the contribution made by peer relationships to student well-being, and thus learning, supports the adoption of NTLS as a strategic policy initiative. Not factored into this discourse, however, is the unintended consequence of students rationally and self-consciously 'colonising' space, not in the positive sense intended by Imms et al. (2016), but in the sense implied by de Certeau's (1984) subversive tactics. 
Evidence of such subversion is evident in narratives that contradict heroic narratives extolling the virtues of working in the radical openness of NTLS. This is clearly evident in teachers' perceptions of student behaviour in NTLS. In a case study developed by Chapman et al. (2014), some teachers likened their NTLS to 'bedlam', and, as a whole, the teachers in this particular school felt they needed additional surveillance support in order to meet the needs of their students. In an account of a teacher and student interaction in their case study, McPherson and Saltmarsh (2017) discuss a teacher's rising distress when one of her students apparently went missing, only later to be found in the glue cupboard. It is noteworthy that these observations by teachers are overwhelmingly behavioural in nature. They have little to do with pedagogy and are situated alongside an underlying assumption that on-task behaviour automatically equates to learning (and, by extension, that agentic behaviour is 'learning behaviour'). Moreover, they do little to reinforce the discourse around happy, borderless learners constructed so carefully by government narratives. What they do indicate instead, are the deliberate and selective choices students make to use available spaces in ways not necessarily formally mandated, as noted in Benade (2017).

Nevertheless, students' utilisation of in-between spaces for social endeavours and diversionary amusement may, arguably, still add value to school, and to learning, and indirectly conforming with the purposes and rationale behind the policy shift towards NTLS (OECD, 2017; Rautio, 2014; Wood, 2019). In Arnesen's et al. (2020) case study of student off-task behaviour in a NTLS, students who were highly ambitious, motivated and high achieving were found to engage in significant off-task practices. Nobody is watching but everything / do is measured is the provocative title adopted by Dargusch and Charteris (2018), who suggest that assessment creates accountability pressure and is effectively a form of silent governance. While they were referring to teacher autonomy, it could be suggested that the same holds for students, thus acting to limit the development of student agency. Arnesen et al. (2020) describe a situation where students lacked motivation to learn unless they understood how their work would impact their grades. In this context, students who know how to balance their off-task endeavours with productive output appears to be the real skill set that is, perversely, being celebrated as 'agency'. While intensified accountability rubs uncomfortably against vaunted notions of agency, it seems 'student agency' has been simplified to finding the 'sweet spot' between work output and off-task practices. This is because it is output alone that is being recognised, examined and measured. If, for teachers, the 'only thing that counts is what can be counted', then the scope for genuine power-sharing with students is severely limited (Dargusch \& Charteris, 2018), further exacerbated by the borderlessness of NTLS, becoming another 'problem' for teachers to manage. Arguably then, any suggestion of 'authentic agency' is a fiction.

\section{Conclusion}

In this article, we have set out to suggest that the notion of student agency be given greater theoretical and philosophical consideration so as to move beyond sanitised and tokenistic notions of agency as student 'voice and choice'. By contemplating the complexity of agentic practices through some provisional themes and ideas, we have raised the prospect of a more detailed consideration of students' agentic demonstration of their spatial competencies within NTLS. Specifically we suggested that the in-between and fringe spaces perhaps not formally considered suitable for learning, are contexts worthy of future study. In reality, not much is yet known about the spatial practices of students in NTLS, as much critical research to date has been inclined (appropriately, we suggest) to teachers' responses to spatial and related pedagogical changes in their workplaces. The ways in which students make agentic choices about how they use space is a domain that now requires detailed and critical consideration. This will enable learning environments scholars and students to deepen their appreciation of the social construction of space, but also develop more nuance in their considerations of policy exhortations to develop student agency. 


\section{Funding details and disclosure statement}

This article is based on a literature review conducted by one of the authors who received a university 'summer studentship' to complete the work. The authors declare there are no conflicts of interest.

\section{Notes on contributors}

Leon Benade works in the School of Education of the Auckland University of Technology. His research interests are teachers' work, school policy, ethics, philosophy in schools, critical pedagogy, and the New Zealand Curriculum, with a current focus on Innovative Learning Environments (ILE) and digital pedagogies. (https://academics.aut.ac.nz/leon.w.benade)

Alastair Wells works in the School of Education of the Auckland University of Technology. He researches notions of space, power and agency as implicated in the development of modern learning environments designed for the implementation of 21st century teaching and learning. (https://academics.aut.ac.nz/alastair.wells)

Kelly Tabor-Price is a Foundation Teacher at Ormiston Junior College, where she develops her interest in 21st century learning, lifelong learning, and the problem of knowledge in a digital age. She is preparing for $\mathrm{PhD}$ study in the School of Education of the Auckland University of Technology. (https://hail.to/ormiston-juniorcollege/publication/MNS4IXC/article/mWoB74z)

\section{ORCID}

Leon Benade (iD) https://orcid.org/0000-0003-3456-0578

Alastair Wells (1) https://orcid.org/0000-0002-6303-7105

\section{References}

Arnesen, T., Arnesen, T. E., \& Elstad, E. (2020). Exploring students' explanations for off-task practices in an innovative learning environment (ILE) using a typology of agency as theoretical framework. Pedagogy, Culture \& Society, 29(4), 651-668. https://doi.org/10.1080/14681366.2020.1777461

Aristotle (2014). Nicomachean ethics. ProQuest Ebook Central https://ebookcentral.proquest.com

Barrett, P., Treves, A., Shmis, T., Ambasz, D., \& Ustinova, M. (2019). The impact of school infrastructure on learning: A synthesis of the evidence. World Bank. https://doi.org/10.1596/978-1-4648-1378-8

Benade, L. (2017). Being a teacher in the $21^{\text {st }}$ century: A critical New Zealand study. Springer Nature.

Benade, L. (2019). Innovative educational facilities' design: Why it matters to education and educators. In M. A. Peters (Ed.), Encyclopedia of Teacher Education. Springer Nature. https://doi.org/10.1007/978-981-131179-6_349-1

Benade, L. (2021a). Flexible and innovative learning spaces: An exploration of parental perspectives on change, consultation and participation. European Educational Research Journal. https://doi.org/10.1177/14749041211041204

Benade, L. (2021b). Theoretical approaches to researching learning spaces. New Zealand Journal of Educational Studies, 56(1), 11-26. https://doi.org/10.1007/s40841-020-00191-z

Bradbeer, C. (2016) Working together in the space-between. In W. Imms, B. Cleveland \& K. Fisher (Eds), Evaluating learning environments. Advances in learning environments research. Sense Publishers.

Brogan, A. (2017). The exilic classroom: Spaces of subversion. Journal of Philosophy of Education, 51(2), 510523. https://doi.org/10.1111/1467-9752.12243

Brown, P., Lauder, H., \& Ashton, D. (2010). The global auction: The broken promises of education, jobs, and incomes. ProQuest Ebook Central. https://ebookcentral.proquest.com

Campbell, L. (2020) Teaching in an inspiring learning space: An investigation of the extent to which one school's innovative learning environment has impacted on teachers' pedagogy and practice. Research Papers in Education, 35(2), 185-204. https://doi.org/10.1080/02671522.2019.1568526

Chapman, A., Randell-Moon, H., Campbell, M. (2014). Students in space: Student practices in non-traditional classrooms. Global Studies of Childhood, 4(1), 39-48. https://doi.org/10.2304\%2Fgsch.2014.4.1.39 
Charteris, J. (2019). Learner agency in innovative spaces. In M. Peters (Ed.), Encyclopedia of Teacher Education. Springer. https://doi.org/10.1007/978-981-13-1179-6_348-1

Charteris, J., \& Smardon, D. (2018). A typology of agency in new generation learning environments: Emerging relational, ecological and new material considerations. Pedagogy, Culture \& Society, 26(1), 5168. https://doi.org/10.1080/14681366.2017.1345975

Dargusch, J., \& Charteris, J. (2018). 'Nobody is watching but everything I do is measured'. Teacher accountability, learner agency and the crisis of control. Australian Journal of Teacher Education, 43(10) 24-40. https://doi.org/10.14221/ajte.2018v43.n10.2

De Certeau, M. (1984). The practice of everyday life. University of California Press.

Deed, C., Cox, P., Dorman, J., Edwards, D., Farrelly, C., Keeffe, M., Lovejoy, V., Mow, L., Sellings, P., Prain, V., Waldrip, B., \& Yager, Z. (2014). Personalised learning in the open classroom: The mutuality of teacher and student agency. International Journal of Pedagogies and Learning, 9(1) 66-75. https://doi.org/10.1080/18334105.2014.11082020

Dovey, K., \& Fisher, K. (2014). Designing for adaptation: The school as socio-spatial assemblage. The Journal of Architecture, 19(1), 43-63. https://doi.org/10.1080/13602365.2014.882376

Foucault, M. (1994). Technologies of the self. In P. Rabinow (Ed.), Ethics: Subjectivity and truth: Essential works of Foucault. Volume 1 (pp. 223-252). Allen Lane- Penguin.

French, R., Imms, W., \& Mahat, M. (2020). Case studies on the transition from traditional classrooms to innovative learning environments: Emerging strategies for success. Improving Schools, 23(2), 175-189. https://doi.org/10.1177/1365480219894408

Imms, W., Cleveland, B., \& Fisher, K. (2016). Pursuing that elusive evidence about what works in learning environment design. In W. Imms, B. Cleveland \& K. Fisher (Eds.), Evaluating learning environments: Snapshots of emerging issues, methods and knowledge (pp. 3-18). Sense Publishers.

Koch, A., Schwennsen, K., Dutton, T. A., \& Smith, D. (2002). The redesign of studio culture: A Report of the AIAS Studio Culture Task Force. The American Institute of Architecture Students. https://www.aias.org/wpcontent/uploads/2016/09/The_Redesign_of_Studio_Culture_2002.pdf

Lefebvre, H. (1991). The production of space. Blackwell.

Leighton, V., \& Byers, T. (2020). All innovative learning environments have one factor in common: A spatially active teacher. Australian Educational Leader, 42(1), 30-33. https://search.informit.org/doi/10.3316/aeipt.226811

Leiringer, R., \& Cardellino, P. (2011). Schools for the twenty-first century: School design and educational transformation. British Educational Research Journal, 376), 915-934. http://doi.org/10.1080/01411926.2010.508512

Lewis, C., Dollery, B., \& Kortt, M. A. (2014). Building the education revolution: Another case of Australian government failure? International Journal of Public Administration, 37(5), 299307. https://doi.org/10.1080/01900692.2013.836660

Mahony, P., \& Hextall, I. (2013). 'Building Schools for the Future': 'Transformation' for social justice or expensive blunder? British Educational Research Journal, 39(5), 853-871. https://doi.org/10.1002/berj.3001

Mameli, C., Grazia, V., \& Molinari, L. (2020). Agency, responsibility and equity in teacher versus student-centred school activities: A comparison between teachers' and learners' perceptions. Journal of Educational Change, 21, 345-361. https://doi.org/10.1007/s10833-019-09366-y

Martin, S. (2006). The classroom environment and children's performance - is there a relationship? In C. Spencer \& M. Blades (Eds.), Children and their environments: Learning, using and designing spaces (pp. 91-107). Cambridge University Press. https://doi.org/10.1017/CBO9780511521232.007

McGregor, J. (2004). Spatiality and the place of the material in schools. Pedagogy, Culture \& Society, 12(3), 347372. https://doi.org/10.1080/14681360400200207

McPherson, A., \& Saltmarsh, S. (2017). Bodies and affect in non-traditional learning spaces. Educational Philosophy and Theory, 49(8), 832-841 https://doi.org/10.1080/00131857.2016.1252904

Minero, E. (2018, March 2). The architecture of ideal learning environments. Edutopia. https://www.edutopia.org/article/architecture-ideal-learning-environments

Ministry of Education (2021). Case studies, research and other sources. https://www.education.govt.nz/school/property-and-transport/projects-and-design/design/designinglearning-environments/case-studies/\#full-reports

Monahan, T. (2002). Flexible space and built pedagogy: Emerging IT embodiments. Inventio, 4 (1). https://publicsurveillance.com/papers/built_pedagogy.pdf

Moore, G. T. \& Lackney, J. A. (1993). School design: Crisis, educational performance and design applications. Children's Environments, 10(2), 99-112. https://www.jstor.org/stable/41514884 
Mulcahy, D., \& Morrison, C. (2017). Re/assembling 'innovative' learning environments: Affective practice and its politics. Educational Philosophy and Theory, 49(8), 749- 758. https://doi.org/10.1080/00131857.2016.1278354

Nair, P. (2014). Blueprint for tomorrow: Redesigning schools for student-centered learning. Harvard Education Press.

Newton, C. (2009). Disciplinary dilemmas: Learning spaces as a discussion between designers and educators. Critical \& Creative Thinking, 17(2), 7-27. http://hdl.handle.net/11343/192320

Organisation for Economic Cooperation and Development. (2013) Innovative Learning Environments. Paris: Educational Research and Innovation, OECD Publishing. Available at: http://doi.org/10.1787/9789264203488-en

Organisation for Economic Cooperation and Development. (2017) The OECD Handbook for Innovative Learning Environments. OECD Publishing. http://www.oecd.org/education/the-oecd-handbook-forinnovative-learning-environments-9789264277274-en.htm

Organisation for Economic Cooperation and Development. (2019). OECD future of education and skills 2030. http://www.oecd.org/education/2030-project/teaching-and-learning/learning/studentagency/Student_Agency_for_2030_concept_note.pdf

Osborne, M. (2016). Innovative Learning Environments. CORE Education White Paper. https://coreed.org/assets/PDFs/Innovative-Learning-Environments.pdf

Pearlman, B. (2010). Designing new learning environments to support 21st century skills. In J. Bellanca \& R. Brandt (Eds.), $21^{\text {st }}$ century skills: Rethinking how students learn (pp. 117-147). Solution Tree.

Peters, R. S. (1970). Ethics and education. Routledge.

Ralph, T., \& Levinson, M. (2019). Survival in the badlands: An exploration of disaffected students' uses of space in a UK secondary school. British Journal of Sociology of Education, 40(8), 1188-1203. https://doi.org/10.1080/01425692.2019.1647089

Rasmussen, L. R. (2019 early online). Disassembling the in-between? Refigurations of the Danish school corridor 1950-2019. Paedagogica Historica. https://doi.org/10.1080/00309230.2019.1669680

Rautio, P. (2014). Mingling and imitating in producing spaces for knowing and being: Insights from a Finnish study of child-matter intra-action. Norwegian Centre for Child Research 21(4), 461-474. https://doi.org/10.1177/0907568213496653

Sigurðardóttir, A. K., \& Hjartarson, T. (2016). The idea and reality of an innovative school: From inventive design to established practice in a new school building. Improving Schools 19(1), 62-79. https://doi.org/10.1177\%2F1365480215612173

Singleton, J. (2015). Head, heart and hands model for transformative learning: Place as context for changing sustainability values. Journal of Sustainability Education, 9, 1-16. http://www.jsedimensions.org/wordpress/wp-content/uploads/2015/03/PDF-Singleton-JSE-March2015-Love- Issue.pdf

Smith, N. (1990). Uneven development: Nature, capital and the production of space. Blackwell.

Tanner, C. K. (2009). Effects of school design on student outcomes. Journal of Educational Administration, 4Л(3), 376-394. https://doi.org/10.1108/09578230910955809

Te Kete Ipurangi. (n.d.-a). Innovative learning environments. https://elearning.tki.org.nz/Teaching/Innovativelearning-environments

Te Kete Ipurangi. (n.d.-b). Learner agency. https://elearning.tki.org.nz/Teaching/Learner-agency

Tondeur, J., Herman, F., De Buck, M., \& Triquet, K. (2017). Classroom biographies: Teaching and learning in evolving material landscapes (c. 1960-2015). European Journal of Education, 52(3), $280-294$. https://doi.org/10.1111/ejed.12228

Veloso, L., Marques, J. S. \& Duarte, A. (2014). Changing education through learning spaces: Impacts of the Portuguese school buildings' renovation programme. Cambridge Journal of Education, 44(3), 401-423. https://doi.org/10.1080/0305764X.2014.921280

Wells, A. (2018). Innovative learning environments as agents of change [Doctoral thesis, Auckland University of Technology]. Tuwhera. http://hdl.handle.net/10292/12058

Wood, A. (2019, June 10). City schools as meeting places. Architecture and Education. https://architectureandeducation.org/2019/06/10/city-schools-as-meeting-places/

Woolner, P., McCarter, S., Wall, K., \& Higgins, S. (2012). Changed learning through changed space: When can a participatory approach to the learning environment challenge preconceptions and alter practice? Improving Schools, 15(1), 45-60. https://doi.org/10.1177\%2F1365480211434796

Woolner, P., Thomas, U., \& Tiplady, L. (2018). Structural change from physical foundations: The role of the environment in enacting school change. Journal of Educational Change 19, 223-242. https://doi.org/10.1007/s10833-018-9317-4 
Wright, N., Thompson, T., \& Horne, T. (2021). Talking spaces: Architects and educators. New Zealand Journal of Educational Studies 56(S1), 45-59. https://doi.org/10.1007/s40841-021-00193-5

Young, F., Cleveland, B., \& Imms, W. (2020). The affordances of innovative learning environments for deep learning: Educators' and architects' perceptions. The Australian Educational Researcher, 47, 693-720. https://doi.org/10.1007/s13384-019-00354-y 